Instructions for authors, subscriptions and further details:

http://ijep.hipatiapress.com

\title{
Predictive Effects of Temperament on Motivation
}

Anna Maria Rawlings, Anna Tapola, Markku Niemivirta

University of Helsinki, Finland

Date of publication: June $24^{\text {th }}, 2017$

Edition period: June 2017 - October 2017

To cite this article: Rawlings, A. M., Tapola, A., \& Niemivirta, M. (2017). Predictive effects of temperament on motivation. International Journal of Educational Psychology, 6(2), 148-182. doi: 10.17583/ijep.2017.2414

To link this article: http://dx.doi.org/10.17583/ijep.2017.2414

\section{PLEASE SCROLL DOWN FOR ARTICLE}

The terms and conditions of use are related to the Open Journal System and to Creative Commons Attribution License (CC-BY). 
IJEP - International Journal of Educational Psychology, Vol. 6 No. 2 June 2017 pp. 148-182

\section{Predictive Effects of Temperament on Motivation}

Anna Maria Rawlings, Anna Tapola, Markku Niemivirta

University of Helsinki

\section{Abstract}

Although temperament and motivation both reflect individual differences in what is perceived as rewarding or threatening, and what is to be approached and what avoided, respectively, we know rather little about how they are connected in educational settings. In this study, we examined how different aspects of temperament (reward and punishment sensitivities) predict the goals students seek to achieve in relation to learning and performance. In Study 1, four dimensions describing students' temperament (sensitivity to punishment, intraindividual reward sensitivity, interindividual reward sensitivity, and positive expressiveness) were uncovered, and in Study 2, these were used to predict students' achievement goal orientations (mastery-intrinsic, mastery-extrinsic, performance-approach, performance-avoidance, and avoidance). The results of exploratory structural equation modeling revealed significant predictions on all achievement goal orientations. In line with theoretical assumptions, sensitivity to punishment was predictive of performance orientations, intraindividual reward sensitivity of mastery orientations, and interindividual reward sensitivity of performance- and avoidance orientations. Positive expressiveness only had weak negative effects on performance orientations. The findings suggest that the goals and outcomes students seek to attain in an educational context are partly dictated by their sensitivity to different environmental cues and the kinds of affective and behavioural responses these typically incite.

Keywords: temperament, motivation, sensitivity to punishment, sensitivity to reward, achievement goal orientations 
IJEP - International Journal of Educational Psychology, Vol. 6 No. 2 June 2017 pp. 148-182

\section{Efectos Predictivos del Temperamento en la Motivación}

Anna Maria Rawlings, Anna Tapola, Markku Niemivirta

University of Helsinki

\section{Resumen}

Aunque el temperamento y la motivación reflejan las diferencias individuales en lo que se percibe como recompensa o amenaza, y lo que se acercará o evitará, respectivamente, sabemos muy poco acerca de su conexión en un entorno educativo. En este estudio, hemos analizado, desde los diferentes aspectos del temperamento (sensibilidad a recompensa y castigo), la predicción de metas relacionadas con el logro. En el estudio 1, se descubrieron 4 dimensiones que describen el temperamento de los estudiantes (sensibilidad al castigo, sensibilidad intraindividual a la recompensa, sensibilidad interindividual a la recompensa y expresividad positiva), y en el estudio 2 estas dimensiones fueron utilizadas para predecir las metas de los estudiantes. Los resultados revelaron predicciones significativas en todas las orientaciones. Coincidiendo con los supuestos teóricos, la sensibilidad al castigo predijo las orientaciones de desempeño, la sensibilidad a la recompensa intraindividual de las orientaciones de dominio y la sensibilidad a las orientaciones de recompensa y evitación del desempeño. Los hallazgos sugieren que las metas y resultados que los estudiantes buscan lograr en un contexto educativo son parcialmente dictados por su sensibilidad a diferentes señales ambientales y los tipos de respuestas afectivas y de comportamiento que típicamente provocan.

Palabras clave: temperamento, motivación, sensibilidad al castigo, sensibilidad a la recompensa, orientaciones para conseguir metas 


\section{Rawlings, Tapola, Niemivirta-Temperament and Motivation}

pproach and avoidance tendencies are fundamental aspects of motivation that instigate goal-directed behaviour towards certain kinds of outcomes (Elliot \& Covington, 2001). In educational settings, students' tendency to prefer and choose certain kinds of goals (i.e., achievement goal orientations) has been found to be linked to various achievement-related (e.g., general school performance, Steinmayr \& Spinath, 2009) and socio-emotional (e.g., well-being, Tuominen-Soini, Salmela-Aro, \& Niemivirta, 2008) outcomes. While marked interindividual differences have been observed in students' goal strivings (for review, see, Kaplan \& Maehr, 2007), less is known about the antecedents to these differences. However, as one possible explanation it has been suggested that individual differences in students' goal tendencies stem partly from temperamental differences in their sensitivity to reward and punishment (Elliot \& Thrash, 2002). While all individuals are considered to be hardwired to approach appetitive and withdraw from or avoid aversive events (Elliot \& Covington, 2001), variation exists in the degree to which behaviour is either motivated or inhibited by these (Corr, 2002; FuentesClaramonte et al., 2016). In addition, it may be possible that individuals vary in what is considered as reward or punishment in the first place. In other words, the sources of reward or punishment may vary (Colder et al., 2011). For now, little is known about how different sources of reward or punishment are perceived, or how they function in an educational context. Consequently, studies elaborating both the structure of temperament from the perspective of students' reward and punishment sensitivities as well as knowledge about their relations to students' goal tendencies are needed. In order to address these questions, in this study we examined, first, the dimensionality and structure of temperamental reward and punishment sensitivities (Study 1), and second, in what ways, and to which extent differences in goal adoption may be traced back to these sensitivities with which students enter the learning situation (Study 2).

\section{Temperament as sensitivity to punishment and sensitivity to reward}

Temperament is the neurobiological basis of personality that accounts for inborn differences in individuals' typical ways of reacting to environmental 
stimuli. This includes, among others, to which kinds of stimuli an individual is particularly sensitive, the propensity for positive or negative affect and the threshold for affective responses being triggered, and how these are manifested in behaviour (Rothbart, 2007). Together with experiences of and encounters with the environment, temperament influences the development of relatively stable emotional, motivational, and behavioural patterns (Rothbart, 2007).

In temperament research, the behavioural reaction to avoid aversive or approach appetitive stimuli is seen as stemming from the innate behavioural inhibition and behavioural approach system (BIS/BAS, Gray \& McNaughton, 2003; for overview, see Corr, 2008). Individual differences in the levels of sensitivity to behavioural inhibition and behavioural approach have an influence on whether environmental stimuli are perceived as representing potentially threatening experiences to be avoided, or rewarding experiences to be sought. For example, new situations can be perceived as threatening by some (Torrubia, Ávila, Moltó, \& Caseras, 2001), or as a source of reward by others (Carver \& White, 1994). Sensitivity to reward activates approach and active pursuit of rewards, such as excitement, novelty, and social acceptance, and is often expressed as positive emotionality and positive anticipation (Colder et al., 2011; Rothbart, 2007; Torrubia et al., 2001). Sensitivity to the threat of punishment activates behavioural inhibition (e.g., withdrawal from situations where one might fail), and is linked to fear and anxiety, negative emotionality, and the anticipation of potential risks and future problems (Carver \& White, 1994; Colder et al., 2011; Cloninger, Svarkic, \& Przybeck, 1993; Rothbart, 2007; Torrubia et al., 2001). Grounding on this conceptualisation, and in keeping with previous research (e.g., Torrubia et al., 2001), we consider temperament in terms of sensitivity to reward and sensitivity to punishment.

The operationalisation of sensitivity to punishment is fairly uniform, but more interpretations exist over the nature and, hence, measuring of sensitivity to reward (see, e.g., Carver \& White, 1994; Cloninger et al., 1993; Torrubia et al., 2001). Although sometimes conceptualised as a single construct (Torrubia et al., 2001), these have more often been viewed as consisting of different dimensions, defined by qualitatively different affective or behavioural responses, or different kinds of appetitive stimuli 


\section{Rawlings, Tapola, Niemivirta-Temperament and Motivation}

and experiences that trigger them (Carver \& White, 1994; Cloninger et al., 1993; Colder et al., 2011). Current research has not systematically addressed the connections of dimensions of reward sensitivity to students' motivational goal tendencies, although it seems likely that in terms of qualitatively different goal preferences, different kinds of rewards also play a different role.

\section{Approach and avoidance tendencies in motivation}

Research into achievement goals has been conducted following two approaches, one of which focuses on goals as task-specific and situational, the other on more generalised goal orientations, which have been found to be relatively stable over time (for review, see, Kaplan \& Maehr, 2007). A large body of achievement goal research utilises a division into mastery and performance goals, with further divisions into approach and avoidance dimensions (Elliot \& McGregor, 2001). Mastery goals involve a focus on learning, understanding, and seeking to gain knowledge and skill improvement (mastery approach), and striving to avoid making mistakes, forgetting what has been learned, or losing capabilities (mastery avoidance), whereas performance goals centre on demonstrating abilities (performance approach) and not exposing inabilities (performance avoidance) (for review, see, Hulleman, Schrager, Bodmann, \& Harackiewicz, 2010). Mastery and performance goals differ in the criteria set for experiencing ability and demonstrating competence, so that mastery goals involve relating one's abilities to the judged difficulty of the task, and performance goals applying normative standards to ability and demonstrating competence in relation to others. Individual differences in proneness to these two classes of goals have been conceptualised, respectively, as task (or mastery) orientation, where the criteria of success refer to an increase in competence, and ego (or performance) orientation, where the criteria of success refer to demonstrations of competence (Nicholls, 1989). A third class of goal orientations, work avoidance, has also been suggested. This refers to an indifferent, passive stance towards schoolwork, and the goal of refraining from exerting effort on it (Nicholls, Patashnick, \& Nolen, 1985).

Overall, mastery goals and orientations have both been connected with 
positive (e.g., persistence, Sideridis \& Kaplan, 2011) and avoidance goals and orientations with negative academic outcomes (e.g., lower interest and grades, Barron \& Harackiewicz, 2003). Performance-approach goals and orientations have been found to be connected with both positive (e.g., higher grades and achievement, Harackiewicz, Barron, Tauer, \& Elliot, 2002), and negative (e.g., emotional exhaustion and stress, Tuominen-Soini et al., 2008) outcomes, and performance-avoidance goals and orientations with negative outcomes (e.g., lower exam performance, Elliot \& McGregor, 2001; cynicism and experiences of inadequacy, Tuominen-Soini, Salmela-Aro, \& Niemivirta, 2012). Consequently, if innate temperamental sensitivities influence the adoption of different goal orientations in learning contexts, students may be placed in a dissimilar position, possibly from the early school years onwards. This may have long-standing effects on their educational trajectories and academic achievement.

\section{The Present Study}

Although approach and avoidance tendencies are central in both temperament and motivation research, we are not aware of studies conducted into the connections between relatively stable goal orientations and reward and punishment sensitivity. In particular, the role of different dimensions of reward remain largely unexplored, as previous research into the relationships between temperament and achievement goals has focused on a two-fold approach-avoidance temperament distinction (Bjørnebekk \& Diseth, 2010; Elliot \& Thrash, 2002, 2010), or has utilised only the fundamental division into behavioural inhibition and behavioural approach (Bjørnebekk, 2007). However, dimensions of behavioural approach have also been discovered to exert qualitatively different effects on motivationally relevant phenomena (e.g., socio-emotional functioning in childhood, Kingsbury, Coplan, Weeks, \& Rose-Krasnor, 2013). Defining temperament in relatively broad terms as approach and avoidance only may therefore result in some lack of specificity. This highlights the need for further research, including considerations on operationalisation. The present research addresses this issue, by means of two sub-studies.

In Study 1, we examined the dimensionality of temperament, with a 
particular focus on identifying different dimensions of reward sensitivity. In order to achieve this, we utilised a measure consisting of items adapted from existing instruments (Carver \& White, 1994; Cloninger et al., 1993; Colder \& O'Connor, 2004; Rothbart, 2007; Torrubia et al., 2001) to cover punishment sensitivity and also capture different aspects of reward presumably pertinent in achievement-related educational settings. In Study 2 , we investigated the predictive relationships between sensitivity to punishment and sensitivity to reward and achievement goal orientations, using this measure.

\section{Study 1}

The aim of this study was to examine the dimensionality of temperament, with a particular focus on identifying different dimensions of reward sensitivity. Research sees punishment sensitivity fairly uniformly as consisting of sensitivity to failure, shyness, withdrawal, and avoidance of threatening or novel situations (Carver \& White, 1994; Colder \& al., 2011; Torrubia et al., 2001). Conceptualisations and operationalisations of reward dimensions have been more varied, and have also covered a range of appetitive stimuli (e.g., sexuality or monetary rewards, Torrubia et al., 2001) that do not seem to bear particular relevance with regard to students' goal strivings in learning situations. Sources of and behavioural responses to reward that appear meaningful in terms of motivation and goal striving in an educational setting include enjoyment of novelty, attention and praise, and positive emotional reactivity (Carver \& White, 1994; Cloninger et al., 1993; Colder \& O'Connor, 2004; Colder et al., 2011; Rothbart, 2007; Torrubia et al., 2001). Based on previous literature and empirical research, these reward dimensions may be considered as separable by the source of actual or anticipated reward being either internal or external. Thus, the measure compiled for the purposes of the present research utilises this division (see Table 1). Internal, intraindividual reward sensitivity describes an individual's sensitivity to rewards derived from one's thoughts, inner states, and actions, manifesting as enjoyment of and seeking novelty, and enthusiasm and excitement over one's successes (Carver \& White, 1994; Cloninger et al., 1993; Colder \& O’Connor, 2004; Rothbart, 2007). As 
regards sensitivity to external reward, we focus on interindividual reward sensitivity, which entails seeking reward from social attention, praise, and success (Colder \& O’Connor, 2004; Torrubia et al., 2001; see also, Cloninger et al., 1993; Colder et al., 2011). For both sensitivity to punishment and sensitivity to reward, it was deemed important that the items would describe situations and experiences relevant in learning contexts.

Table 1.

Item Sources for Measuring Dimensions of Reward and Punishment Sensitivity.

\begin{tabular}{|c|c|c|}
\hline $\begin{array}{l}\text { Sensitivity to } \\
\text { Punishment }\end{array}$ & $\begin{array}{l}\text { Sensitivity to } \\
\text { Intraindividual Reward }\end{array}$ & $\begin{array}{l}\text { Sensitivity to } \\
\text { Interindividual Reward }\end{array}$ \\
\hline $\begin{array}{l}\text { Withdrawal; avoidance } \\
\text { of difficult situations; } \\
\text { aversion to novelty } \\
\text { (Colder \& O'Connor, } \\
\text { 2004; Torrubia et al., } \\
\text { 2001) }\end{array}$ & $\begin{array}{l}\text { Enjoyment of and seeking } \\
\text { novelty } \\
\text { (Carver \& White, 1994; } \\
\text { Cloninger et al., 1993; } \\
\text { Rothbart, 2007) }\end{array}$ & $\begin{array}{l}\text { Seeking attention } \\
\text { (Colder \& O'Connor, } \\
\text { 2004; Torrubia et al., } \\
\text { 2001) }\end{array}$ \\
\hline $\begin{array}{l}\text { Shyness and discomfort } \\
\text { (Carver \& White, 1994; } \\
\text { Cloninger et al., 1993; } \\
\text { Colder \& O'onnor, } \\
\text { 2004; Rothbart; 2007; } \\
\text { Torrubia et al., 2001) } \\
\text { Sensitivity to failure } \\
\text { (Carver \& White, 1994; } \\
\text { Colder \& O'Connor, } \\
\text { 2004; Torrubia et al., } \\
\text { 2001) }\end{array}$ & $\begin{array}{l}\text { Enthusiasm, excitement } \\
\text { (Carver \& White, 1994; } \\
\text { Cloninger et al., 1993; } \\
\text { Colder \& O'Connor, } \\
\text { 2004; Rothbart, 2007) }\end{array}$ & $\begin{array}{l}\text { Impressing others } \\
\text { (Colder \& O'Connor, } \\
\text { 2004; Torrubia et al., } \\
\text { 2001) }\end{array}$ \\
\hline
\end{tabular}

\section{Method}

\section{Participants and Procedure}

In Finland, comprehensive education lasts nine years (ages 7-16), after which close to $95 \%$ of students continue to upper secondary education 
(Statistics Finland, 2014), for which there are two overall options: general upper secondary school with a more academic focus, and vocational upper secondary school providing a qualification in a particular profession. More than $50 \%$ of students continue to general upper secondary school (Statistics Finland, 2014). Both are completed in three to four years. The participants in this study were the whole age cohort of first-year students $(N=157$, age 16 17, girls 57\%) from the general upper secondary school of a middle-sized, middle-class town in Central Finland. The participants, hence, represent a fairly typical sample of youths from similar, non-metropolitan towns with a population relatively homogenous as regards socio-economic status, and ethnically almost entirely native Finnish. The students completed the questionnaire rating their temperamental sensitivities at the end of the school year. Participation was voluntary, and the participants were assured of the confidentiality of their responses.

\section{Measures}

To measure temperament, we compiled a scale to cover sensitivity to punishment (5 items, e.g., "I withdraw easily in difficult or awkward situations", depicting behavioural inhibition, shyness, discomfort, sensitivity to failure; Carver \& White, 1994; Colder \& O'Connor, 2004; Rothbart; 2007; Torrubia et al., 2001); and two reward sensitivity scales reflecting differences in sources of reward: internal, intraindividual reward sensitivity (5 items, e.g., "I express my excitement and enjoyment openly, when I succeed at something", "I will readily seek out novel situations", depicting enthusiasm, excitement, enjoyment of novelty; Carver \& White, 1994; Cloninger et al., 1993; Colder \& O'Connor, 2004; Rothbart, 2007); and external, interindividual reward sensitivity (4 items, e.g., "I often do things just to be praised", depicting seeking attention and praise, impressing others; Colder \& O'Connor, 2004; Torrubia et al., 2001). The students rated the items on a scale of 1 ("Not at all true") to 7 ("Completely true"). The full list of items is given in Table 2.

\section{Analyses}

The data were analysed with Exploratory Structural Equation Modeling (ESEM) with Geomin rotation using Mplus statistics software (Muthén \& 
Muthén, 1998-2015). ESEM was chosen as the method for analysis, as the assumption of confirmatory factor analysis (CFA) that each item load only onto the expected factor, with a zero loading on others, was seen both as overly restrictive for use within an exploratory setting, and as artificially suppressing possible cross-loadings between factors (Marsh, Morin, Parker, \& Kaur, 2014), which may, in fact, depict the interacting nature of the phenomena studied (see, Corr \& McNaughton, 2008). Unlike exploratory factor analysis (EFA), ESEM calculates fit indices comparable to those obtained in CFA, thus providing statistical criteria for evaluating different factor solutions. In addition to the $\chi^{2}$ value, the standardised root mean squared residual (SRMR, recommended cut-off point $<.08)$, comparative fit index (CFI, recommended cut-off point $>$. 95), and the root mean square of error approximation (RMSEA, recommended cut-off point <.06) were used to assess model fit (see, Hu \& Bentler, 1999). Descriptive statistics and Cronbach's alphas for composite scores were calculated using SPSS 23.

\section{Results}

Factor analyses using ESEM with Geomin rotation were conducted to examine the dimensionality of temperamental reward and punishment sensitivities. A three-factor model based on our operationalisation was first tested. The fit was fair, $\chi^{2}(52)=101.131, p<.001$; SRMR $=.041$; RMSEA $=.078(90 \% \mathrm{CI}=.055, .100)$; CFI $=.929$, but the factor structure was somewhat unclear, with two reward sensitivity items ("I will readily seek out novel situations"; "I think it is exciting to get into new and surprising situations") failing to load significantly on any factor. Adding one factor resulted in a good fit, $\chi^{2}(41)=62.946, p=.015$; SRMR $=.030$; RMSEA = $.058(90 \% \mathrm{CI}=.026, .086)$; CFI $=.968$. The factors corresponded to the expected division into sensitivity to punishment and interindividual and intraindividual reward dimensions, but with the intraindividual dimension further separating into 1) enjoyment and seeking of novelty and 2) a tendency for excitement and open expression of positive emotions about personal successes. The item "I will gladly be the centre of attention" loaded positively on the intended interindividual reward sensitivity factor $(.62, p<.001)$, but also negatively on the sensitivity to punishment factor ($.39, p<.01)$. As interindividual reward sensitivity describes the need or 
strong desire for social success, such as attention, and sensitivity to punishment a tendency for withdrawal, the cross-loading was seen as understandable. The loading of the punishment sensitivity item "I feel very uncomfortable in new situations and places" was found somewhat unclear, as it loaded on the intended sensitivity to punishment factor $(.39, p<.001)$, the interindividual reward sensitivity factor $(.32, p<.01)$, and the noveltyseeking reward sensitivity factor $(-.37, p<.01)$. Considering the as yet exploratory nature of the measure, the relatively small numerus, the theoretical meaningfulness of the factors on the whole, and the good model fit, the factor solution was accepted without further alterations, with the view of examining it further in Study 2. The explained variance ranged between .31-.77, with all items significant at $p<.001$. The factors were labelled intraindividual reward sensitivity for novelty-seeking (SRi[nternal]NS), interindividual reward sensitivity (SRe[xternal]), sensitivity to punishment $(S P)$, and intraindividual reward sensitivity depicting a tendency for enthusiasm and expression of delight over one's successes (positive expressiveness, SRiPE). All factor loadings and explained variance of items are given in Table 2. 
Table 2.

Factor Loadings (ESEM) of Reward and Punishment Sensitivity, and Explained Variance of Items (Study 1).

\begin{tabular}{|c|c|c|c|c|c|}
\hline Factors and Items & 1 & 2 & 3 & 4 & $\mathrm{R}^{2}$ \\
\hline \multicolumn{6}{|l|}{1 INTRAINDIVIDUAL REWARD SENSITIVITY - NOVELTY-SEEKING } \\
\hline I will readily seek out novel situations. & .89 & -.06 & .03 & -.00 & .77 \\
\hline $\begin{array}{l}\text { I think it is exciting to get into new and surprising situations. } \\
2 \text { INTERINDIVIDUAL REWARD SENSITIVITY }\end{array}$ & .60 & .10 & -.07 & .04 & .43 \\
\hline I often do things just to be praised. & -.03 & .73 & -.02 & .05 & .54 \\
\hline I will gladly be the centre of attention. & .04 & .62 & -.39 & .03 & .43 \\
\hline I sometimes act hastily just to get an immediate reward or praise. & -.07 & .59 & .07 & .09 & .41 \\
\hline I often aim to impress other people. & .21 & .49 & .12 & -.04 & .31 \\
\hline \multicolumn{6}{|l|}{3 SENSITIVITY TO PUNISHMENT } \\
\hline I withdraw easily in difficult or awkward situations. & .01 & .17 & .63 & -.05 & .49 \\
\hline I avoid talking or performing in public (e.g., at lectures). & -.32 & -.05 & .61 & .05 & .63 \\
\hline I am easily shy in the company of people I don't know and in new situations. & -.29 & .02 & .59 & .05 & .57 \\
\hline I get upset easily if I am criticised or told off. & .12 & .28 & .52 & .02 & .39 \\
\hline I feel very uncomfortable in new situations and places. & -.37 & .32 & .39 & -.08 & .61 \\
\hline \multicolumn{5}{|l|}{4 INTRAINDIVIDUAL REWARD SENSITIVITY - POSITIVE } & \\
\hline I express my excitement and enjoyment openly, when I succeed at something. & -.02 & .20 & -.02 & .74 & .64 \\
\hline I don't hold back my joy and enthusiasm when something nice happens to me. & .03 & -.14 & .06 & .73 & .50 \\
\hline I get excited about new things easily. & .32 & .04 & -.17 & .43 & .47 \\
\hline
\end{tabular}

Notes. Significant $(p<.01)$ factor loadings above $|.30|$ given in bold; $p<.001$ for all $\mathbf{R}^{2}$. 
SRiNS correlated negatively with SP and positively with SRiPE. SRe correlated positively with SP. All factor correlations as well as descriptive statistics and Cronbach's alphas calculated from composite scores are presented in Table 3.

The separation of the three SR factors implies that our measure is sensitive enough to capture different dimensions of reward. The extracted dimensions are theoretically meaningful and, for the main part, in line with our expectations, supporting our suggestion that they may be related to motivation in different ways. This will be examined in Study 2.

Table 3.

Factor Correlations for Latent Variables, and Descriptive Statistics and Cronbach's Alphas from Composite Scores (Study 1).

\begin{tabular}{lccccccc}
\hline & 1 & 2 & 3 & 4 & $M$ & $S D$ & $\begin{array}{c}\text { Cronbach's } \\
\text { Alpha }\end{array}$ \\
\hline 1 SRiNS & - & & & & 4.06 & 1.22 & .72 \\
2 SRe & .05 & - & & & 3.10 & 1.02 & .68 \\
3 SP & $-.46^{* * *}$ & $.28^{*}$ & - & & 3.60 & 1.28 & .82 \\
4 SRiPE & $.29 * *$ & .22 & -.19 & - & 4.56 & 1.17 & .71 \\
\hline
\end{tabular}

Note. $* p<.05 ; * * p<.01 ; * * * p<.001$

\section{Study 2}

The tendencies to approach desired outcomes of action, such as learning or demonstrating competence, or avoiding undesirable ones, such as failing in front of others, are important features defining students' goal orientations (Hulleman et al., 2010). In this respect, individuals can be seen to differ in their propensity to focus more strongly either on a desired outcome and approaching it, or on an undesirable outcome and avoiding it. This could be seen as reflecting individual differences in the approach behaviour associated with temperamental sensitivity to reward, and the withdrawal behaviour associated with sensitivity to punishment, respectively (Elliot \& Thrash, 2002). 
In this study, we utilised a five-fold conceptualisation of achievement goal orientations (Niemivirta, Pulkka, Tapola, \& Tuominen, 2017). The conceptualisation follows the division into mastery, performance, and avoidance orientations (see, Nicholls, 1989; Nicholls et al., 1985), with further separations into intrinsically and extrinsically-based mastery goals, as well as approach and avoidance types of performance goals. The five orientations defined include the mastery-intrinsic orientation that describes the goal of learning for the sake of itself, where success is evaluated in an intrinsic, intraindividual way (e.g., improving one's skills, developing competence, deepening understanding). The mastery-extrinsic orientation similarly implicates the goal of mastery, but here, success is defined in an absolute way (e.g., in the form of high grades). As in the bulk of achievement goal research (e.g., Elliot \& Thrash, 2002; Sideridis \& Kaplan, 2011), the two performance goal orientations are considered from an approach and avoidance perspective. The performanceapproach orientation entails the goal of demonstrating competence by striving for relative success (outperforming others), whereas the performance-avoidance orientation entails the goal of avoiding judgements of incompetence or failure. The avoidance orientation describes the aim of avoiding expending effort as much as possible, and only completing the compulsory minimum of tasks.

A considerable body of motivation research has focused on the links between achievement goals and goal orientations and various educational outcomes, for example, interest (Harackiewicz, Durik, Barron, LinnenbrinkGarcia, \& Tauer, 2008; Tapola, Jaakkola, \& Niemivirta, 2014), well-being (Kaplan \& Maehr, 1999; Tuominen-Soini et al., 2008), achievement (Barron \& Harackiewicz, 2003; Elliot \& McGregor, 2001), and students' perceptions and evaluations of the learning environment and of their own course performance (Pulkka \& Niemivirta, 2013; Tapola \& Niemivirta, 2008). The observed relative stability over time and suggested dispositional nature of achievement goal orientations (Pulkka \& Niemivirta, 2013; Tuominen-Soini et al., 2012) support considering them as connected with temperamental reward and punishment sensitivity.

Connections between temperament and achievement goals have been observed in some previous research. Overall, approach temperament 


\section{Rawlings, Tapola, Niemivirta-Temperament and Motivation}

has been found to be linked with approach goals and avoidance temperament with avoidance goals (Bjørnebekk, 2007; Bjørnebekk \& Diseth, 2010; Elliot \& Thrash, 2002, 2010), although some of the observed effects have not been entirely unambiguous. The discovered connections make it plausible to assume that temperamental tendencies do influence students' motivational goal tendencies, yet the relatively broad operationalisation of temperament may contribute to a loss of specificity in the observed predictions. We therefore sought to investigate these predictions from a more differentiated perspective.

The task of the present study was, firstly, to examine whether the four-fold factor structure of sensitivity to punishment (SP), interindividual reward sensitivity (SRe), intraindividual reward sensitivity for novelty (SRiNS), and intraindividual reward sensitivity with tendency for positive expressiveness (SRiPE) that was uncovered in Study 1 would be replicated here.

Secondly, we examined what kinds of predictive effects (statistical, not causal) temperamental reward and punishment sensitivity exert on students' achievement goal orientations. We expected mastery orientations to be predicted by novelty-seeking, as they describe an interest in learning, and interest is seen as linked with curiosity and seeking novelty (Renninger \& Hidi, 2011; Silvia \& Sanders, 2010). In contrast, as sensitivity to punishment sensitises an individual to experience novelty as potentially threatening (Colder \& O'Connor, 2004; Torrubia et al., 2001), and encountering new content and challenges is inevitable in a learning situation, sensitivity to punishment may be a negative predictor for the mastery orientations. We expected performance-approach orientation to be predicted by interindividual reward sensitivity, as the need for, or a focus on, social rewards such as attention or praise might make students more prone to striving for relative success (i.e., being better than others, see, Colder \& O'Connor, 2004; Torrubia et al., 2001). As sensitivity to punishment has been considered as including avoidance of demonstrating skills for fear of public embarrassment (Colder \& O'Connor, 2004; Colder et al., 2011; Torrubia et al., 2001), we expected it to predict performance-avoidance orientation, which, in turn, is considered as a tendency to avoid learning or performance situations where public failure is seen as possible (Tuominen- 
Soini et al., 2008). As regards the avoidance orientation, we assume a negative prediction by the intraindividual reward sensitivities. Given that the latter are expected to support the enjoyment of novelty and delight in one's successes, an inverse relation to the tendency to want to avoid effort and to experience low incentive value in terms of schoolwork, seems likely.

\section{Method}

\section{Participants and Procedure}

The participants were university students in the fields of humanities, social sciences, and education $\left(N=506 ; 86 \%\right.$ women; $\left.M_{\text {age }}=25.07, S D=5.47\right)$ invited to take part in the study with an email containing a link to an electronic questionnaire. The distribution of gender is fairly representative of the population of university students in these fields (Statistics Finland, 2015). Students' contact information was obtained from university email lists. Participation was voluntary, and the participants were assured of the confidentiality of their responses.

\section{Measures}

The set of items described and examined in Study 1 was used for measuring temperamental reward and punishment sensitivities. Achievement goal orientations were measured using the instrument validated in a large body of previous research (e.g., Niemivirta, 2002; Pulkka \& Niemivirta, 2013; Tuominen-Soini et al., 2008, 2012). The measure taps five orientations, each with 3 items on a scale of 1 ("Not at all true") to 7 ("Completely true"): mastery-intrinsic (e.g., "I study in order to learn new things"), masteryextrinsic (e.g., "An important goal for me is to do well in my studies"), performance-approach (e.g., "An important goal for me in my studies is to do better than the other students"), performance-avoidance (e.g., "I try to avoid situations in which I may fail or make mistakes"), and avoidance orientation (e.g., "I try to get away with as little effort as possible in my studies”). 


\section{Analyses}

The data were analysed with ESEM-SEM with Geomin rotation, with a combination of EFA and CFA factors, using Mplus statistics software (Muthén \& Muthén, 1998-2015). In line with the methodological choice made in Study 1, ESEM was seen as more appropriate for use with an instrument tapping complex interconnected phenomena (see, Marsh et al., 2014), such as temperament dimensions. Due to the interconnected nature of temperamental sensitivities (see, Corr \& McNaughton, 2008), we considered it reasonable to allow for theoretically meaningful crossloadings, rather than suppress them. CFA was specified for achievement goal orientation items as the distinct factorial structure has been validated in previous studies. All achievement goal orientation variables were regressed on all temperament variables, without any fixed specifications of relationships. Through this, we sought to establish the independent effect of each temperament dimension on each achievement goal orientation while controlling for the effects of the other dimensions.

As in Study 1, the $\chi^{2}$ value, the standardised root mean squared residual (SRMR, recommended cut-off point $<.08$ ), the root mean square of error approximation (RMSEA, recommended cut-off point $<.06$ ), and the comparative fit index (CFI, recommended cut-off point $>.95$ ) were used to assess model fit (see, Hu \& Bentler, 1999). Descriptive statistics and Cronbach's alphas for composite scores were calculated using SPSS 23.

\section{Results}

ESEM-SEM analysis with Geomin rotation was used to examine the factor structure and the predictive effects. The fit for a model with four temperament factors as derived from Study 1 predicting the five achievement goal orientations was partially satisfactory, $\chi^{2}(311)=964.633$, $p<.001 ; \mathrm{SRMR}=.056$; RMSEA $=.064(90 \% \mathrm{CI}=.060, .069)$; CFI $=.914$. An inspection of the model modification indices showed an item measuring the performance-avoidance orientation ("It is important to me that I don't fail in front of other students") to cross-load on the performance-approach factor. As this was seen as theoretically sound, the item was freed to cross- 
load, which improved the fit, $\chi^{2}(310)=859.965, p<.001$; SRMR $=.050$; RMSEA $=.059(90 \% \mathrm{CI}=.055, .064) ; \mathrm{CFI}=.928$. Whilst the CFI was somewhat lower than the proposed cut-off point of $>.95$, as the other fit indices were adequate, and as the factor loadings were theoretically meaningful, this model was chosen with no further alterations made.

The factor structure of the temperament dimensions was examined. The final model corresponded to the four dimensions observed in Study 1: SP, SRe, SRiPE, and SRiNS, although the item "I get excited about new things easily", which in Study 1 loaded on SRiPE, here loaded on SRiNS. The item "I feel very uncomfortable in new situations and places" that had unclear factor loadings in Study 1 here loaded well on the intended SP factor $(.74, p<.001)$, but the SP item "I get upset easily if I am criticized or told off' loaded also onto $\operatorname{SRe}(.45, p<.001$, and $.31, p<.001$, respectively). The explained variance for all items was significant at $p<.001$, and ranged between .27-.97. Factor loadings and explained variance for the temperament dimension items are given in Table 4. Regarding achievement goal orientations, apart from the performance-avoidance item "It is important to me that I don't fail in front of other students" that was freed to cross-load onto performance-approach, the items loaded well onto the theoretically expected factors. The factor loadings and explained variance for achievement goal orientations are given in Table 5. 


\section{Rawlings, Tapola, Niemivirta-Temperament and Motivation}

Table 4.

Factor Loadings (ESEM) of Reward and Punishment Sensitivity, and Explained Variance of Items (Study 2).

\begin{tabular}{|c|c|c|c|c|c|}
\hline Factors and Items & 1 & 2 & 3 & 4 & $\mathrm{R}^{2}$ \\
\hline \multicolumn{6}{|l|}{1 SENSITIVITY TO PUNISHMENT } \\
\hline I am easily shy in the company of people I don't know and in new situations. & .80 & -.05 & -.01 & .03 & .62 \\
\hline I feel very uncomfortable in new situations and places. & .74 & .16 & -.01 & -.16 & .72 \\
\hline I avoid talking or performing in public (e.g., at lectures). & .69 & -.05 & -.00 & .02 & .46 \\
\hline I withdraw easily in difficult or awkward situations. & .56 & .19 & -.03 & -.05 & .39 \\
\hline I get upset easily if I am criticised or told off. & .45 & .31 & .05 & .10 & .27 \\
\hline \multicolumn{6}{|l|}{2 INTERINDIVIDUAL REWARD SENSITIVITY } \\
\hline I often do things just to be praised. & .15 & .71 & -.04 & -.04 & .53 \\
\hline I often aim to impress other people. & -.07 & .69 & -.01 & .12 & .51 \\
\hline I sometimes act hastily just to get an immediate reward or praise. & .02 & .62 & .01 & -.04 & .39 \\
\hline I will gladly be the centre of attention. & -.40 & .50 & .14 & .01 & .48 \\
\hline \multicolumn{6}{|l|}{3 INTRAINDIVIDUAL REWARD SENSITIVITY - POSITIVE EXPRESSIVENESS } \\
\hline I express my excitement and enjoyment openly, when I succeed at something. & .01 & .03 & .98 & -.01 & .97 \\
\hline I don't hold back my joy and enthusiasm when something nice happens to me. & -.04 & -.02 & .79 & .01 & .65 \\
\hline \multicolumn{6}{|l|}{4 INTRAINDIVIDUAL REWARD SENSITIVITY - NOVELTY-SEEKING } \\
\hline I get excited about new things easily. & .02 & -.04 & .27 & .57 & .47 \\
\hline I will readily seek out novel situations. & -.36 & -.01 & .01 & .57 & .67 \\
\hline I think it is exciting to get into new and surprising situations. & -.42 & .09 & -.03 & .52 & .65 \\
\hline
\end{tabular}

Note. Significant $(p<.01)$ factor loadings above $|.30|$ given in bold; $p<.001$ for all $\mathrm{R}^{2}$. 
Table 5.

Factor Loadings (SEM) of Achievement Goal Orientations, and Explained Variance of Items (Study 2).

\begin{tabular}{|c|c|c|c|c|c|c|}
\hline Factors and Items & 1 & 2 & 3 & 4 & 5 & $\mathrm{R}^{2}$ \\
\hline \multicolumn{7}{|l|}{1 MASTERY-INTRINSIC ORIENTATION } \\
\hline I study in order to learn new things. & .94 & & & & & .88 \\
\hline An important goal for me in my studies is to learn as much as possible. & .84 & & & & & .71 \\
\hline & .84 & & & & & .71 \\
\hline \multicolumn{7}{|l|}{2 MASTERY-EXTRINSIC ORIENTATION } \\
\hline An important goal for me is to do well in my studies. & & .90 & & & & .82 \\
\hline My goal is to succeed in my studies. & & .84 & & & & .71 \\
\hline It is important to me that I get good grades. & & .75 & & & & .56 \\
\hline \multicolumn{7}{|l|}{3 PERFORMANCE-APPROACH ORIENTATION } \\
\hline An important goal for me in my studies is to do better than the other students. & & & .65 & & & .43 \\
\hline I feel good, if I manage to demonstrate to other students that I'm competent. & & & .64 & & & .42 \\
\hline It is important to me that others think I'm able and competent. & & & .59 & & & .35 \\
\hline \multicolumn{7}{|l|}{4 PERFORMANCE-AVOIDANCE ORIENTATION } \\
\hline I try to avoid situations in which I may fail or make mistakes. & & & & .90 & & .81 \\
\hline I try to avoid situations in which I may appear dumb or incompetent. & & & & .67 & & .44 \\
\hline It is important to me that I don't fail in front of other students. & & & .48 & .41 & & .54 \\
\hline \multicolumn{7}{|l|}{5 AVOIDANCE ORIENTATION } \\
\hline I try to get away with as little effort as possible in my studies. & & & & & .87 & .75 \\
\hline I always try to get away with as little effort as possible in my studies. & & & & & .80 & .63 \\
\hline I am particularly satisfied if I don't have to work much for my studies. & & & & & .71 & .50 \\
\hline
\end{tabular}

Note. All factor loadings $p<.001 ; \mathrm{R}^{2} p<.001$ for all items. 


\section{Rawlings, Tapola, Niemivirta-Temperament and Motivation}

A negative correlation was observed between SP and both SRiPE and SRiNS. SRe and SRiPE correlated positively, as did the two intraindividual reward sensitivity factors SRiPE and SRiNS. The factor correlations of all latent variables, and descriptive statistics and Cronbach's alphas calculated from composite scores, are given in Table 6.

Table 6.

Factor Correlations for Latent Variables, and Descriptive Statistics and Cronbach's Alphas from Composite Scores (Study 2).

\begin{tabular}{|c|c|c|c|c|c|c|c|c|c|c|c|}
\hline Variable & 1 & 2 & 3 & 4 & 5 & 6 & 7 & 8 & $M$ & $S D$ & $\begin{array}{c}\text { Cronbach's } \\
\text { Alpha }\end{array}$ \\
\hline $1 \mathrm{SP}$ & - & & & & & & & & 3.95 & 1.27 & .79 \\
\hline $2 \mathrm{SRe}$ & .03 & - & & & & & & & 3.45 & 1.09 & .71 \\
\hline 3 SRiPE & $-.32 * * *$ & $.17 * * *$ & - & & & & & & 5.12 & 1.42 & .88 \\
\hline 4 SRiNS & $-.49 * * *$ & .06 & $.32 * * *$ & - & & & & & 4.85 & 1.17 & .78 \\
\hline 5 Mastery-Intrinsic Orientation & $-.23 * * *$ & $-.27 * * *$ & $.18 * * *$ & $.53 * * *$ & - & & & & 5.58 & 1.14 & .91 \\
\hline 6 Mastery-Extrinsic Orientation & .06 & .00 & .02 & $.17 * * *$ & $.42 * * *$ & - & & & 5.26 & 1.10 & .71 \\
\hline $\begin{array}{l}7 \text { Performance-Approach } \\
\text { Orientation }\end{array}$ & $.16^{* * * *}$ & $.62 * * *$ & -.01 & $.14 * *$ & .06 & $.57 * * *$ & - & & 4.56 & 1.07 & .64 \\
\hline $\begin{array}{l}8 \text { Performance-Avoidance } \\
\text { Orientation }\end{array}$ & $.78 * * *$ & $.32 * * *$ & $-.30 * * *$ & $-.44 * * *$ & $-.36 * * *$ & .05 & $.36 * * *$ & - & 4.15 & 1.27 & .75 \\
\hline 9 Avoidance Orientation & $.22 * * *$ & $.32 * * *$ & $-.09 *$ & $-.29 * * *$ & $-.59 * * *$ & $-.51 * * *$ & -.03 & $.29 * * *$ & 3.82 & 1.40 & .83 \\
\hline
\end{tabular}

Note. $* p<.05 ; * * p<.01 ; * * * p<.001$ 
Regarding the predictions of temperament on achievement goal orientations, the mastery-intrinsic orientation was predicted positively by SRiNS and negatively by SRe. Mastery-extrinsic orientation was predicted positively by SRiNS and SP. Performance-approach was predicted by all temperament sensitivities: positively by SRe, SRiNS, and SP, and negatively by SRiPE. Performance-avoidance was predicted positively by SP and SRe, and negatively by SRiPE. Finally, the avoidance orientation was predicted positively by $\mathrm{SRe}$ and negatively by SRiNS. The model significantly explained the variance of all but the mastery-extrinsic orientation, with the explained variance ranging between $6 \%$ (mastery-extrinsic orientation) and $71 \%$ (performance-avoidance orientation). All significant effects and explained variance are illustrated in Figure 1.

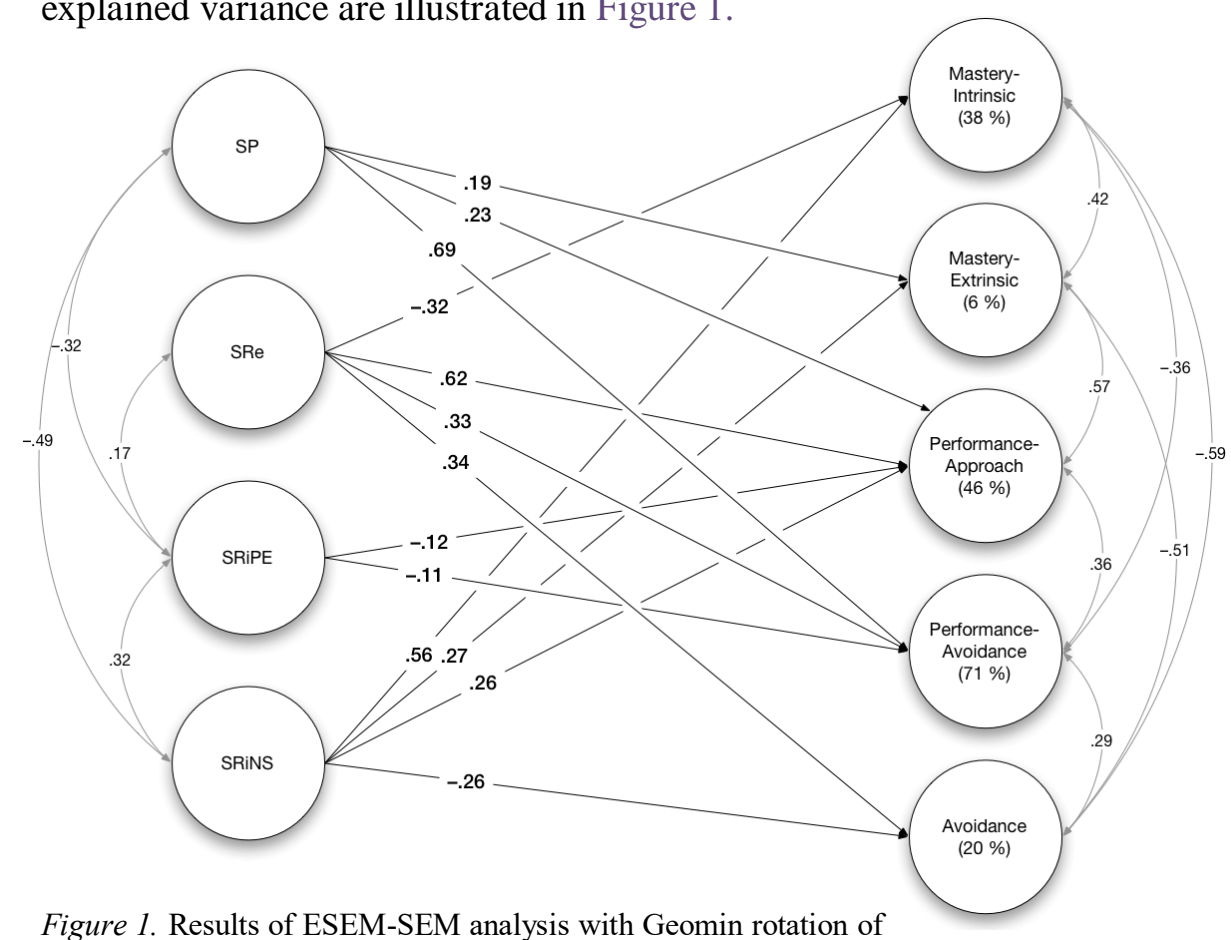
achievement goal orientations (confirmatory factors) predicted from temperamental reward and punishment sensitivities (exploratory factors). For clarity, observed variables and corresponding factor loadings are omitted, and only significant $(p<.05)$ effects $(\beta)$ and correlations are reported. 


\section{Discussion}

The present research examined, by means of two sub-studies, the dimensionality of temperament and the predictive effects of temperament on achievement-related motivation. Study 1 focused on the structure of temperamental sensitivities and, in particular, on uncovering dimensions of reward sensitivity relevant in an educational setting. Study 2 sought to replicate the factor structure of temperamental sensitivities uncovered in Study 1, using a different data set, and to predict achievement goal orientations from sensitivity to punishment and sensitivity to reward.

\section{Structure of temperamental sensitivities}

Study 1 revealed a four-factor structure of temperamental sensitivities (sensitivity to punishment, sensitivity to interindividual reward, and two intraindividual reward sensitivities, namely, novelty-seeking and positive expressiveness) that was mostly in line with the expectations we derived from theoretical considerations and previous research. This structure was for the most part replicated in Study 2, the main difference being the loading of one intraindividual reward sensitivity item on the positive-expressive reward sensitivity factor in Study 1, and on the novelty-seeking factor in Study 2. The wording of the item may render it too open to interpretation, which may affect the usability of the item. This should be given consideration in future research using the measure. A positive correlation between sensitivity to punishment and interindividual reward sensitivity was observed in Study 1, whereas in Study 2, there was a zero-correlation between the two factors. This may, to some extent, reflect the difference in age of the participants in the two studies, in that the relationships between temperamental sensitivities may differ as a function of maturation. This possibility remains for future research to explore.

In line with our expectation, sensitivity to punishment factored into one dimension, consisting of sensitivity to failure, shyness and discomfort, and behavioural inhibition. The unidimensionality of sensitivity to punishment is consistent with much previous research (Carver \& White, 1994; Torrubia et al., 2001), although in some recent studies, it has been considered as multidimensional (Colder et al., 2011; Corr \& Cooper, 2016). 
Considerably more items have been used in these latter studies to operationalise sensitivity to punishment. It remains for future research to consider whether including more items in the scale would be fruitful for investigating the possibility of different aspects of punishment sensitivity exerting differential effects on motivation.

As we expected, a separate dimension of sensitivity to interindividual reward, describing reward derived from social acceptance or success, such as attention or praise, was discovered. Although sometimes conceptualised as an aspect of a distinct temperament dimension (e.g., reward dependence, Cloninger et al., 1993), or empirically discovered to factor into a separate reward sensitivity dimension (Colder et al., 2011), this sensitivity has often been included as part of a unidimensional sensitivity to reward (Torrubia et al., 2001), or left unexplored (Carver \& White, 1994). However, the robust nature of the factor as well as its distinct effects on achievement goal orientations suggest that considering it separately from other reward sensitivities seems fruitful. Somewhat against the expected single intraindividual reward dimension (reward derived from one's own actions, goal attainment, and inner states), it was found to separate further into two distinct dimensions. These dimensions depict a tendency for enthusiasm and delight in personal successes, which we labelled positive expressiveness, and a sensitivity to seek and react positively to novelty. These factors bear some resemblance to recent findings by Corr and Cooper (2016), who labelled their corresponding factors reward reactivity (including items describing excitement and delight regarding personal achievements, as well as their open expression, resembling our positive-expressiveness factor) and reward interest (describing enjoyment of novelty, and resembling our novelty-seeking factor).

The positive or zero correlations between sensitivity to punishment and interindividual reward sensitivity observed in the present research may indicate that avoidance of failure may have a central role also for the latter temperamental sensitivity. Sensitivity to punishment may influence avoidance of public failure by those for whom social acceptance is important, and who are otherwise not prone to withdrawal from social situations. This finding corresponds to connections observed in previous research, where responsiveness to social approval has been found to 


\section{Rawlings, Tapola, Niemivirta-Temperament and Motivation}

correlate positively with anxiety, and to have a zero correlation with fear/shyness (Colder et al., 2011). Likewise, Cloninger and colleagues' (1993) reward dependency, defined as including dependency on social reward, has been found to be a joint predictor of behavioural inhibition, together with harm avoidance (Mardaga \& Hansenne, 2007).

Punishment sensitivity was also found to be negatively associated with both intraindividual reward sensitivities. This corresponds to previous studies where behavioural inhibition has been found to be negatively connected with novelty-seeking (Caseras, Àvila, \& Torrubia, 2003; see also, Rothbart, 2007), although some modest positive correlations with dimensions of behavioural approach have also been found (Corr \& Cooper, 2016). Interindividual reward sensitivity was positively associated with positive expressiveness in Study 2. This is consistent with findings in previous research, where responsiveness to social approval has correlated positively with other reward sensitivity dimensions (Colder et al., 2011). The observed positive correlations between the two intraindividual reward sensitivities in both studies, in turn, may be taken to reflect the positive connections between the reward reactivity and reward interest dimensions of behavioural approach discovered in previous research (Corr \& Cooper, 2016).

Overall, the similarity of both the factor structures and the interrelationships of temperament dimensions observed in the two studies supported the validity of the compiled set of items for measuring temperamental sensitivities.

\section{Predictive effects of reward and punishment sensitivity on achievement goal orientations}

Study 2 took the examination further into using the measure to predict achievement goal orientations, conceptualised as mastery-intrinsic, masteryextrinsic, performance-approach, performance-avoidance, and avoidance (Niemivirta et al., 2017). Note that by this, we are referring to statistical predictions, not causal inferences. We are aware of the limitations of using cross-sectional data for such a design, but find it nevertheless useful as we seek to extract independent effects of temperamental sensitivities on goal orientations. 
The temperamental sensitivities extracted using our compiled measure predicted all orientations in a theoretically meaningful way, and the explained variance was statistically significant for all apart from the mastery-extrinsic orientation.

Behavioural inhibition (conceptualised in the present research as sensitivity to punishment) and behavioural approach (conceptualised here as reward sensitivity) are considered as operating together as joint subsystems (Corr, 2002). Our results, in uncovering patterns of temperamental sensitivities predicting distinct motivational orientations, appear in line with this. To summarise, novelty-seeking being associated with enjoyment of learning, sensitivity to punishment with performance concerns, and seeking or needing social acceptance and praise being related to high performanceor avoidance orientations are the key predictions observed in this study.

Both mastery orientations were predicted positively by noveltyseeking. It therefore appears that novelty-seeking is a temperamental sensitivity that supports experiencing learning as inherently motivating. The prediction is in line with our expectations, as well as with the links noted in previous research between novelty-seeking, curiosity, and interest (Renninger \& Hidi, 2011; Silvia \& Sanders, 2010). The result also corresponds to previous studies linking behavioural approach and mastery orientation (Elliot \& Thrash, 2002), and behavioural approach and study engagement (van Beek, Kranenburg, Taris, \& Schaufeli, 2013). There were, however, also differences in the predictions. Mastery-intrinsic was also predicted negatively by the interindividual reward sensitivity, indicating that low levels of the need for praise and attention from others seems to support the enjoyment of learning for its own sake. Mastery-extrinsic was predicted positively by sensitivity to punishment. This sensitivity may introduce performance concerns by directing an individual's focus on potential threats in the environment (e.g., possibility of failure). High novelty-seeking together with sensitivity to punishment may thereby induce pressure to demonstrate competence by achieving at a high level, which is characteristic of the mastery-extrinsic orientation (Grant \& Dweck, 2003; Niemivirta, 2002). It should be noted that due to the non-significance of explained variance of the mastery-extrinsic orientation, conclusions about it and comparisons between the two mastery orientations are to be drawn carefully. 


\section{Rawlings, Tapola, Niemivirta-Temperament and Motivation}

This said, the observed similarities and differences in predictions support considering the two as separate, although related, motivational orientations.

Both performance orientations were predicted positively by sensitivity to punishment and interindividual reward sensitivity, with interindividual reward sensitivity being the strongest predictor for performance-approach and sensitivity to punishment for performanceavoidance, in line with our expectations. Both were also predicted negatively by positive expressiveness, the effect being greater on performance-avoidance. Little emphasis being placed on enjoyment of one's successes may heighten the importance of social attention and praise as sources of reward. This, together with performance concerns arising from punishment sensitivity, may in the case of both orientations play a role in learning situations being perceived as performance situations involving social comparison. However, only performance-approach was predicted positively by novelty-seeking, which, given its positive prediction on the mastery orientations, appears to support learning motivation. Sensitivity to social reward together with novelty-seeking may influence experiencing learning, rather than as an end in itself, as a means to an end, which is typical of performance orientation (Nicholls, 1989). In addition to demonstrating ability, this end may also entail acquiring social attention and praise. Regarding the differences between the two performance orientations, novelty-seeking was not a predictor of performance-avoidance, and the predictive effect exerted on performance-avoidance by sensitivity to punishment was stronger than on performance-approach. This pattern may induce uncertainty about one's ability to perform successfully in front of other people whose approval may be an important source of reward, and heighten the experienced importance of not being judged as failing, which, in turn, is associated with the performance-avoidance orientation (Niemivirta, 2002).

In line with our expectations, the avoidance orientation was predicted negatively by novelty-seeking, while the observed positive effect from interindividual reward sensitivity was not assumed. This pattern of predictions is the direct opposite to the predictions on mastery-intrinsic orientation. Given that the two orientations describe an entirely different approach to goal setting regarding academic pursuits and achievement 
(Kaplan \& Maehr, 2007; Nicholls, 1989), the result seems understandable. The prediction further supports considering novelty-seeking as a temperamental sensitivity that supports striving towards learning, and conversely, that disinterest in or even dislike of novelty appears to direct focus away from academic pursuits and effort. That the need for social approval and praise was also associated with work avoidance orientation is in line with suggestions that the interests of students endorsing avoidance goals lie in other than academic areas (Archer, 1994; Nicholls, 1989).

Our results indicate that taking into account not only sensitivity to punishment and sensitivity to reward, but also different sources of reward and their potentially different effects on motivation, is a useful approach for uncovering possible antecedents to the adoption of different goal strivings. Considering sources of reward separately, and hence being able to examine the relative strengths of their effects, may increase understanding of the connections between temperament and goal strivings, and expand upon the results obtained in previous research.

\section{Limitations and Suggestions for Future Research}

There are some limitations to the present research. As with all research utilising self-report questionnaires, response bias may be an issue. The factor structure of temperamental sensitivities uncovered in the present research included a single sensitivity to punishment dimension. However, recent research has considered sensitivity to punishment as separable into two dimensions (Colder et al., 2011; see also, Corr \& Cooper, 2016), and this and their possible differential effects on motivation remains an issue to be explored in future research. Developing a larger pool of items would improve the content validity of the measure used in the present research. As both studies were conducted with cross-sectional data, no assertion as to the direction of causality can be made. The relatively homogenous socioeconomic background and ethnicity of the participants in both studies, as well as the high proportion of women (86\%) in Study 2, also presents limitations with regard to extrapolation of the findings to men and students from different backgrounds. However, our results indicate a promising opening for the examination of the ways temperament may shape the 


\section{Rawlings, Tapola, Niemivirta-Temperament and Motivation}

formation and adoption of stable motivational orientations. Future research should be conducted in a longitudinal framework, to examine the development and stability of temperament and its relationship with motivation further, and with participants from more varied backgrounds, to increase the generalisability of the findings.

\section{Conclusions}

Our results suggest that sensitivity to punishment and sensitivity to reward contribute to students' relatively stable motivational orientations. In particular, taking into account also the effects of qualitatively different kinds of reward dimensions on students' goal strivings appears salient. Together with sensitivity to punishment, these dimensions formed patterns of predictions that were found related to the adoption of different goal orientations. As different goal orientations are known to influence both achievement and socio-emotional outcomes in beneficial or disadvantageous ways, increased understanding of the antecedents to their development and adoption holds importance for both educational research and practice. For example, high levels of temperamental sensitivity to punishment or interindividual reward may induce experiencing instruction or certain pedagogical practices, such as excessive assessment or an ethos of competition, as threatening or otherwise unpleasant. This may contribute to underachievement or increased school exhaustion. Heightened awareness of these innate individual differences would therefore be important in both classroom practices and teacher training. Recognising the mechanisms linking temperament and motivation as well as their developmental nature holds importance for educational research. Future studies should focus on longitudinal settings to examine the stability and development of both temperamental sensitivities and their influence on goal orientations.

\section{Acknowledgements}

This research was supported by the Academy of Finland (grant \#1279742 to MN). The first author has a doctoral student position at the University of Helsinki Doctoral Programme in Psychology, Learning and Communication. The authors wish to thank the members of the Motivation, Learning, and Well-Being research group for support and comments. We thank Guadalupe Blanco Velasco for the Spanish translation of the abstract, and all students and teachers for participation. The authors have no conflict of interest to declare. 


\section{References}

Archer, J. (1994). Achievement goals as a measure of motivation in university students. Contemporary Educational Psychology, 19(4), 430- 446. doi:10.1006/ceps.1994.1031

Barron, K. E., \& Harackiewicz, J. M. (2003). Revisiting the benefits of performance-approach goals in the college classroom: Exploring the role of goals in advanced college courses. International Journal of Educational Research, 39(4), 357-374. doi:10.1016/j.ijer.2004.06.004

Bjørnebekk, G. (2007). Reinforcement sensitivity theory and major motivational and self-regulatory processes in children. Personality and Individual Differences, 43(8), 1908-1990. doi:10.1016/j.paid.2007.06.010

Bjørnebekk, G. \& Diseth, Å. (2010). Approach and avoidance temperaments and achievement goals among children. Personality and Individual Differences, 49(8), 938-943. doi:10.1016/j.paid.2010.07.034

Carver, C. S., \& White, T. L. (1994). Behavioral inhibition, behavioral activation, and affective responses to impending reward and punishment: The BIS/BAS scales. Journal of Personality and Social Psychology, 67(2), 319-333. doi: 10.1037/00223514.67.2.319

Caseras, X., Àvila, C., \& Torrubia, R. (2003). The measurement of individual differences in behavioural inhibition and behavioural activation systems: a comparison of personality scales. Personality and Individual Differences, 34(6), 999-1013. doi:10.1016/S01918869(02)00084-3

Cloninger, C. R., Svarkic, D. M., \& Przybeck, T. R. (1993). A

psychobiological model of temperament and character. Archives of General Psychiatry, 50(12), 975-990. doi:10.1001/archpsyc.1993.01820240059008

Colder, C. R. \& O'Connor, R. M. (2004). Gray's reinforcement sensitivity model and child psychopathology: laboratory and questionnaire assessment of the BAS and BIS. Journal of Abnormal Child Psychology, 32(4), 435-451. doi: 
178 Rawlings, Tapola, Niemivirta-Temperament and Motivation

\subsection{3/B:JACP.0000030296.54122.b6}

Colder, C. R., Trucco, E. M., Lopez, H. I., Hawk Jr., L. W., Read, J. P., Lengua, L. J., \& Eiden, R. D. (2011). Revised reinforcement sensitivity theory and laboratory assessment of BIS and BAS in children. Journal of Research in Personality, 45(2), 198-207. doi:10.1016/j.jrp.2011.01.005

Corr, P. J. (2002). JA Gray's reinforcement sensitivity theory: Tests of the joint subsystems hypothesis of anxiety and impulsivity. Personality and Individual Differences, 33(4), 511-532. doi:10.1016/S0191-8869(01)00170-2

Corr, P. J. (2008). Reinforcement sensitivity theory (RST): introduction. In P. J. Corr (Ed.), The Reinforcement Sensitivity Theory of Personality. New York, NY, US: Cambridge University Press. 143.

Corr, P. J., \& Cooper, A. J. (2016, February 4). The Reinforcement Sensitivity Theory of Personality Questionnaire (RST-PQ):

Development and validation. Psychological Assessment. Advance online publication. doi: 10.1037 /pas0000273

Corr, P. J. \& McNaughton, N. (2008). Reinforcement sensitivity theory and personality. In P. J. Corr (Ed.), The Reinforcement Sensitivity Theory of Personality. New York, NY, US: Cambridge University Press. 155-187.

Elliot, A. J., \& Covington, M. V. (2001). Approach and avoidance motivation. Educational Psychology Review, 13(2), 73-92. doi: 10.1023/A:1009009018235

Elliot, A. J. \& McGregor, H. A. (2001). A 2 x 2 achievement goal framework. Journal of Personality and Social Psychology, 80(3), 501-519. doi: 10.1037/0022-3514.80.3.501

Elliot, A. J. \& Thrash, T. M. (2002). Approach-avoidance motivation in personality: Approach and avoidance temperaments and goals. Journal of Personality and Social Psychology, 82(5), 804-818. doi: 10.1037/0022-3514.82.5.804

Elliot, A. J. \& Thrash, T. M. (2010). Approach and avoidance temperament as basic dimensions of personality. Journal of Personality, 78(3), 865-906. doi: 10.1111/j.1467-6494.2010.00636.x 
Fuentes-Claramonte, P., Ávila, C., Rodríguez-Pujadas, A., Costumero, V., Ventura-Campos, N., Bustamante, J. C., ... \& Barrós-Loscertales, A. (2016). Characterizing individual differences in reward sensitivity from the brain networks involved in response inhibition. Neuroimage, 124, 287-299. doi:

10.1016/j.neuroimage.2015.08.067

Grant, H., \& Dweck, C. S. (2003). Clarifying achievement goals and their impact. Journal of Personality and Social Psychology, 85(3), 541553. doi: $10.1037 / 0022-3514.85 .3 .541$

Gray, J. A., \& McNaughton, N. (2003). The Neuropsychology of Anxiety. An Enquiry into the Functions of the Septo-Hippocampal System (2nd ed.). Oxford, UK: Oxford University Press.

Harackiewicz, J. M., Barron, K. E., Tauer, J. M., \& Elliot, A. J. (2002). Predicting success in college: A longitudinal study of achievement goals and ability measures as predictors of interest and performance from freshman year through graduation. Journal of Educational Psychology, 94(3), 562-575. doi: 10.1037/00220663.94.3.562

Harackiewicz, J. M., Durik, A. M., Barron, K. E., Linnenbrink-Garcia, L., \& Tauer, J. M. (2008). The role of achievement goals in the development of interest: Reciprocal relations between achievement goals, interest, and performance. Journal of Educational Psychology, 100(1), 105-122. doi: 10.1037/0022-0663.100.1.105

Hulleman, C. S., Schrager, S. M., Bodmann, S. M., \& Harackiewicz, J. M. (2010). A meta-analytical review of achievement goal measures: Different labels for the same constructs or different constructs with similar labels? Psychological Bulletin, 136(3), 442-449. doi: 10.1037/a00118947

Hu, L., \& Bentler, P. M. (1999). Cutoff criteria for fit indexes in covariance structure analysis: Conventional criteria versus new alternatives. Structural Equation Modeling: A Multidisciplinary Journal, 6(1), 1-55. doi: 10.1080/10705519909540118

Kaplan, A., \& Maehr, M. L. (1999). Achievement goals and student wellbeing. Contemporary Educational Psychology, 24(4), 330-358. doi:10.1006/ceps.1999.0993 
Kaplan, A., \& Maehr, M. L. (2007). The contributions and prospects of goal orientation theory. Educational Psychological Review, 19(2), 141-184. doi: 10.1007/s10648-006-9012-5

Kingsbury, A., Coplan, R. J., Weeks, M., \& Rose-Krasnor, L. (2013). Covering all the BAS's: A closer look at the links between BIS, BAS, and socio-emotional functioning in childhood. Personality and Individual Differences, 55(5), 521-526.

doi:10.1016/j.paid.2013.04.021

Mardaga, S., \& Hansenne, M. (2007). Relationships between Cloninger's biosocial model of personality and the behavioral inhibition/approach systems (BIS/BAS). Personality and Individual Differences, 42(4), 715-722. doi:10.1016/j.paid.2006.08.013

Marsh, H. W., Morin, A. J. S., Parker, P. D., and Kaur, G. (2014). Exploratory Structural Equation Modeling: An integration of the best features of exploratory and confirmatory factor analysis. Annual Clinical Review of Psychology, 10, 85-110. doi: 10.1146/annurev-clinpsy-032813-153700

Muthén, L. K. \& Muthén, B. (1998-2015). Mplus User's Guide. Seventh Edition. Los Angeles, CA: Muthén \& Muthén.

Nicholls, J. G. (1989). The Competitive Ethos and Democratic Education. Cambridge, MA: Harvard University Press.

Nicholls, J. G., Patashnick, M. \& Nolen, S. B. (1985). Adolescents' theories of education. Journal of Educational Psychology, 77(6), 683-692. doi: 10.1037/0022-0663.77.6.683

Niemivirta, M. (2002). Motivation and performance in context: The influence of goal orientations and instructional setting on situational appraisals and task performance. Psychologia, 45(4), 250-270. doi: 10.2117/psysoc.2002.250

Niemivirta, M., Pulkka, A.-T., Tapola, A., \& Tuominen, H. (2017). Achievement goal orientations: A person-oriented approach. To appear in A. Renninger \& S. E. Hidi (Eds.), Handbook on Motivation and Learning. Cambridge University Press.

Pulkka, A., \& Niemivirta, M. (2013). Adult students' achievement goal orientations and evaluations of the learning environment: a person- 
centred longitudinal analysis. Educational Research and Evaluation: An International Journal on Theory and Practice 19(4), 297-322. doi: 10.1080/13803611.2013.767741

Renninger, K. A., \& Hidi, S. (2011). Revisiting the conceptualization, measurement, and generation of interest. Educational Psychologist, 46(3), 168-184. doi: $10.1080 / 00461520.2011 .587723$

Rothbart, M. K. (2007). Temperament, development, and personality. Current Directions in Psychological Science, 16(4), 207-212. doi: 10.1111/j.1467-8721.2007.00505.x

Sideridis, G. D., \& Kaplan, A. (2011). Achievement goals and persistence across tasks: The roles of failure and success. The Journal of Experimental Education, 79(4), 429-451.doi:

10.1080/00220973.2010.539634

Silvia, P. J., \& Sanders, C. E. (2010). Why are smart people curious? Fluid intelligence, openness to experience, and interest. Learning and Individual Differences, 20(3), 242-245. doi:10.1016/j.lindif.2010.01.006

Statistics Finland. (2014). Retrieved May 29, 2017, from http://www.stat.fi/til/khak/2014/khak_2014_2016-0322_tau_001_en.html

Statistics Finland. (2015). Retrieved May 29, 2017, from http://www.stat.fi/til/yop/2015/yop_2015_2016-0510 tie 001 en.html

Steinmayr, R. \& Spinath, B. (2009). The importance of motivation as a predictor of school achievement. Learning and Individual Differences, 19(1), 80-90. doi:10.1016/j.lindif.2008.05.004

Tapola, A., Jaakkola, T., \& Niemivirta, M. (2014). The influence of achievement goal orientations and task concreteness on situational interest. The Journal of Experimental Education, 82(4), 455-479. doi: 10.1080/00220973.2013.813370

Tapola, A., \& Niemivirta, M. (2008). The role of achievement goal orientations in students' perceptions of and preferences for classroom environment. British Journal of Educational Psychology, 78(2), 291-312. doi: 10.1348/000709907X205272 
Torrubia, R., Ávila, C., Moltó, J. \& Caseras, X. (2001). The sensitivity to punishment and sensitivity to reward questionnaire (SPSRQ) as a measure of Gray's anxiety and impulsivity dimensions.

Personality and Individual Differences, 31(4), 837-862. doi:10.1016/S0191-8869(00)00183-5

Tuominen-Soini, H., Salmela-Aro, K., \& Niemivirta, M. (2008). Achievement goal orientations and subjective well-being: A person-centred analysis. Learning and Instruction, 18(3), 251-266. doi: 10.1016/j.learninstruc.2007.05.003

Tuominen-Soini, H., Salmela-Aro, K. \& Niemivirta, M. (2012).

Achievement goal orientations and academic well-being across the transition to upper secondary education. Learning and Individual Differences, 22(3), 290-305. doi:10.1016/j.lindif.2012.01.002 van Beek, I., Kranenburg, I. C., Taris, T. W., \& Schaufeli, W. B. (2013). BIS- and BAS-activation and study outcomes: A mediation study. Personality and Individual Differences, 55(5), 474-479. doi:10.1016/j.paid.2013.04.013

Anna Maria Rawlings, MEd, is a researcher at the Faculty of Educational Sciences, University of Helsinki.

Anna Tapola, $\mathrm{PhD}$, is a researcher at the Faculty of Educational Sciences, University of Helsinki.

Markku Niemivirta, PhD, is Professor at the Faculty of Educational Sciences, University of Oslo, and Research Director at the Faculty of Educational Sciences, University of Helsinki.

Contact Address: Faculty of Educational Sciences, University of Helsinki P.O. Box 9 FI-00014 Finland Email: anna.rawlings@helsinki.fi 